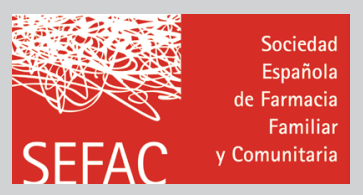

\title{
Un congreso para estar más cerca y llegar más lejos
}

\section{Eduardo Satué de Velasco', Ana Mateos Lardiés}

1. Presidente del comité organizador del VII Congreso Nacional de Farmacéuticos Comunitarios.

2. Presidenta del comité científico del VII Congreso Nacional de Farmacéuticos Comunitarios.

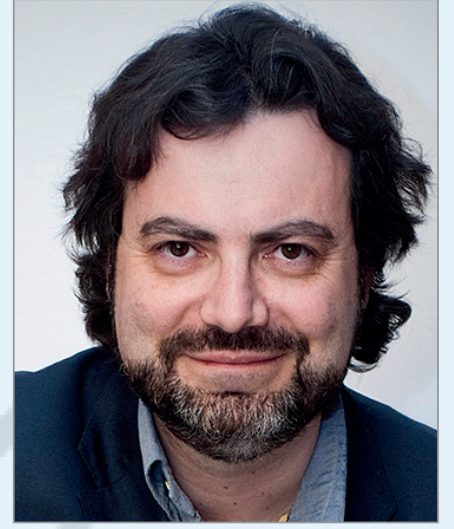

Eduardo Satué de Velasco

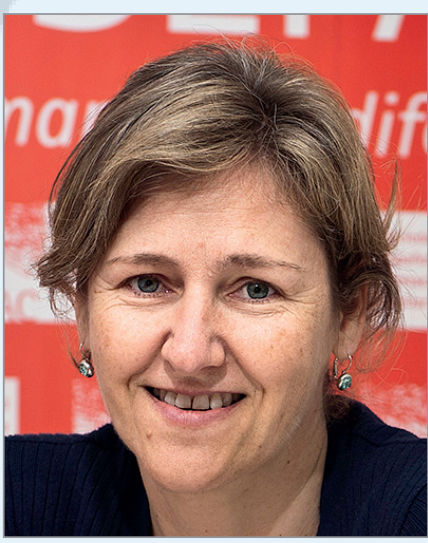

Ana Mateos Lardiés

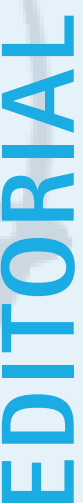

El VII Congreso de Farmacéuticos Comunitarios ya está a la vuelta de la esquina. Una impresionante progresión en visitantes, comunicaciones, talleres, estands... avalan su vocación de servir a la profesión desde su primera edición en Tarragona en 2004. Sin embargo, las preguntas que debemos hacernos no son: ¿Es necesario un congreso farmacéutico para la profesión? ¿Nos puede ayudar a mejorar a nivel asistencial? SEFAC, como única sociedad científica y profesional específica de la farmacia comunitaria, aspira a que sus congresos cumplan con los tres objetivos básicos que debe tener un congreso científico:

a) Formar a los profesionales, a través de la actualización de contenidos, compartir descubrimientos, estimulación de la investigación $\mathrm{y}$, en suma, proporcionarles las mejores herramientas, cognitivas y materiales, para ejercer su labor.

b) Movilizarla, planteando desde una autocrítica constructiva qué cambios son precisos introducir para permitir que la profesión pueda continuar sirviendo óptimamente a la sociedad, sin caer en flagelos inútiles ni autocomplacencias estériles.

c) Finalmente, servir de interlocutor con la sociedad, mostrando, a través del diálogo en nuestro caso con entidades, otras sociedades científicas, asociaciones de pacientes, Administración, medios de comunicación... los avances, retos, debates y compromisos que afronta la profesión.

Éste siempre ha sido nuestro anhelo y una vez más confiamos en poder cumplirlo, con humildad pero con el convencimiento de que un congreso no puede ser un constructo artificial donde se amontonen sesiones, sino que debe responder a una hoja de ruta, a un esfuerzo colectivo, coordinado y con sentido que impulsa a la profesión en una dirección con porvenir. SEFAC siempre ha tenido claro que la farmacia asistencial es el presente y el futuro de la profesión y así ha ido construyendo un itinerario, congreso a congreso, desde la filosofía general de la atención farmacéutica al planteamiento concreto de los servicios profesionales farmacéuticos (SPF), la retribución de los servicios, la colaboración multidisciplinar en patología crónica y en esta nueva edición abordando una cuestión esencial en nuestro quehacer diario: el papel del farmacéutico comunitario en la optimización de la prescripción a través de herramientas contempladas por la Federación Internacional Farmacéutica (FIP) como son la prescripción complementaria y la farmacia colaborativa. La normativa en varios países desarrollados está permitiendo al farmacéutico tener un papel mucho más activo en el proceso de prescripción. Este proceso descarga al médico de parte de la carga de trabajo, optimiza la prestación al paciente y ofrece una ampliación de responsabilidades y desempeño profesional al farmacéutico plenamente justificada dada su preparación. Éste es uno de los nuevos retos que debe afrontar la profesión en los próximos tiempos y confiamos que el congreso sirva de espoleta de salida para este nuevo escenario.

La ambición de este reto no debe hacernos olvidar la continuidad de los retos presentes y en los que SEFAC ha sido pionera: la estrategia de dispensación de medicamentos de diagnóstico hospitalario en farmacia comunitaria y contemplar el pago por servicio, que ya se planteó en 2012; la administración de determinados inyectables en la propia farmacia, herramienta usada en otros países para complementar, nunca sustituir, a otros profesionales y mejorar las cuota de vacunación y para permitir el 
tratamiento directamente observado a pacientes complejos; el papel del farmacéutico en las estrategias de cronicidad, el futuro de las nuevas tecnologías en su aplicabilidad a los nuevos SPF y, por último, el enorme reto que suponen las últimas directivas de la Unión Europea sobre recertificación, que más pronto que tarde supondrá una realidad de valoración de todos los profesionales sanitarios. Si a esto sumamos una lista de ponentes con grandes conocimientos y experiencia (nacionales e internacionales), un poderoso elenco de talleres y simposios que hacen hincapié en cómo implantar desde el punto de vista práctico los SPF en la farmacia, tales como el control de la HTA y el riesgo vascular, la cesación tabáquica, el seguimiento de asma y EPOC, sistemas personalizados de dosificación (SPD) y diabetes, confiamos en abordar al menos aquellas cuestiones más innovadoras y, a la vez, las más necesarias para generar un mensaje de utilidad y modernidad hacia la sociedad. Todo responde a una estrategia de actualización y enfoque de la farmacia comunitaria hacia una plataforma presta- dora de servicios sanitarios, donde sea el conocimiento del profesional y su actuación asistencial por encima del producto, el eje de su estrategia y actividad.

En cualquier caso, la fuerza de un congreso se mide no solo por sus contenidos, sino sobre todo, porque permite canalizar el esfuerzo colectivo, la ilusión, el trabajo y los proyectos que día a día los socios y no socios que colaboran con SEFAC aportan. Son estas personas las que llenan y dotan de sentido un congreso, pues son ellos el alma y la fuerza de la sociedad científica y profesional de la farmacia comunitaria, que se ofrece a toda la profesión y a la sociedad en su conjunto. Y es precisamente ese esfuerzo e ilusión el que debe encontrar cauces de comunicación con todos los compañeros que trabajan en solitario, a menudo desbordados por las ingentes exigencias del sistema administrativo, pero que precisan, como todos los demás, de apoyo para orientar y profesionalizar su farmacia. Éste pretende ser su congreso porque la farmacia comunitaria necesariamente ha de estar más cerca y llegar más lejos.

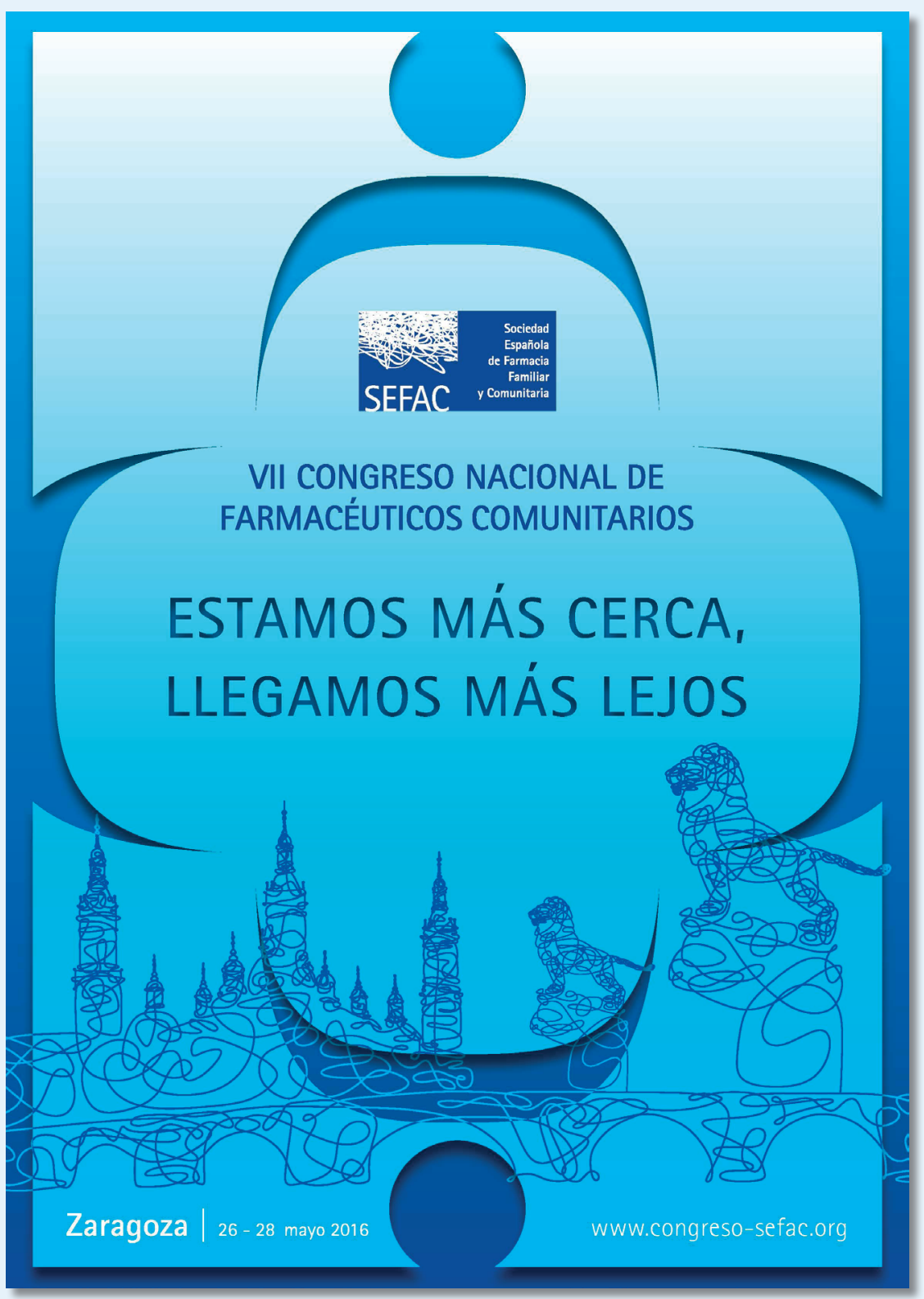

